\title{
RAIMOND GAITA E A COMPREENSÃO DA MORALIDADE A PARTIR DO RECONHECIMENTO DA REALIDADE DO OUTRO
}

\author{
Susie Kovalczyk dos Santos ${ }^{1}$ \\ Universidade Federal de Santa Maria (UFSM) \\ (D) https://orcid.org/0000-0001-5285-222X
}

\section{RESUMO:}

Explora-se no presente artigo a função que o reconhecimento do outro desempenha para a moralidade no âmbito da obra Good and Evil: An Absolute Conception, de Raimond Gaita, a partir da centralidade da noção de remorso, entendido como a recordação do significado moral para o agente daquilo que ele fez. Serão resgatados os exemplos partir dos quais Gaita pretende enfatizar o peso da moralidade e o significado de se fazer o mal moralmente para alguém. Não se pode compreender, segundo o filósofo, uma situação como moralmente problemática se não for inteligível que quem a realizou deveria sentir um remorso genuíno diante constatação do mal gerado a partir de suas ações.

PALAVRAS-CHAVE: Gaita; Moral; Remorso; Reconhecimento

\section{RAIMOND GAITA AND THE UNDERSTANDING OF MORALITY FROM THE RECOGNITION OF THE REALITY OF THE OTHER}

\begin{abstract}
:
This paper explores the role that the recognition of the other plays for morality in Raimond Gaita's Good and Evil: An Absolute Conception, from the centrality of the notion of remorse, understood as the remembrance of moral meaning for the agent of what he did. The examples from which Gaita intends to emphasize the weight of morality and the meaning of doing evil morally for someone will be rescued. One can not understand, according to the philosopher, a situation as morally problematic if it is not intelligible that whoever realized it should feel a genuine remorse in the face of the evil generated by their actions.
\end{abstract}

KEYWORDS: Gaita; Moral; Remorse; Recognition.

\footnotetext{
${ }^{1}$ Doutoranda em Filosofia pela Universidade Federal de Santa Maria (UFSM), Rio Grande do Sul Brasil. E-mail: lczyk.susie@gmail.com. 
Em Good and Evil: An Absolute Conception, o filósofo contemporâneo Raimond Gaita defende que o reconhecimento do outro desempenha um papel fundamental para a moralidade. $O$ presente artigo aborda a função do reconhecimento na obra em questão, com ênfase na noção de remorso e em sua importância para a moralidade. A concepção de Gaita, aqui explorada, consiste em uma alternativa às teorias morais das tradições racionalistas, tais como as teorias deontológicas e utilitaristas. Os quatro momentos desta investigação consistem em, primeiramente, clarificar a concepção de remorso no âmbito da filosofia de Gaita, passando à explicação, na seção "A indissolubilidade do remorso genuíno", de por que o sentimento de remorso não pode ser atenuado. A distinção efetuada por Gaita entre a culpa e o remorso é explicada no terceiro momento, na seção intitulada "Remorso: o caso da holandesa", seguida, por fim, da consideração do papel de outros sentimentos para a moralidade, apresentada na seção "Comprometimento e reconhecimento".

Quanto ao conteúdo da moralidade, Gaita se afasta das concepções racionalistas deontológicas e utilitaristas. Em linhas gerais, para uma concepção deontológica o que está em questão na avaliação do conteúdo da moralidade é a motivação do agente, a exemplo da proposta de Immanuel Kant (1969). De acordo com a teoria kantiana, um ato moralmente errado envolve a violação de um princípio ou máxima moral tal como o prescrito pelo imperativo categórico. Teorias utilitaristas, por sua vez, avaliam a moralidade de uma ação a partir da consideração da utilidade que dela decorre, visto que são teorias consequencialistas. Os termos em que a noção de utilidade é definida variam de uma teoria para a outra. Por exemplo, no âmbito das teorias de Jeremy Bentham (1996) e de John Stuart Mill (1998), representantes do utilitarismo clássico, uma ação será considerada moralmente preferível em relação a outras vias de ação possíveis se a sua realização produzir a maior quantidade de bem, para o máximo de pessoas envolvidas, em comparação com o que poderia resultar das alternativas consideradas.

Gaita se distancia dessas tradições ao defender que a perplexidade de alguém ao errar moralmente se deve ao reconhecimento, através do sentimento de remorso, da realidade daqueles impactados por tal ato e do mal que foi feito a eles. Enfatiza, assim, a noção de remorso para a compreensão do que significa um problema ser de natureza moral, bem como para a compreensão do discurso moral em geral e do sentido de expressões nele empregadas, tais como "moralmente errado", "moralmente terrível", "moralmente o mesmo que". Apostando na centralidade do remorso, o autor sugere que as filosofias morais da modernidade não o fizeram a propósito de uma hostilidade com relação à culpa e a sentimentos de culpa. $\mathrm{O}$ prejuízo dessa opção, segundo Gaita, é que ela ameaça tanto o entendimento apropriado de noções de bem e mal, quanto o senso da própria humanidade e a compreensão da realidade das outras pessoas. Ao longo de sua argumentação, o autor fornece uma série de exemplos, alguns dos quais retomados neste artigo, que são fundamentais para a compreensão de sua teoria e da própria moralidade, por tornar compreensível o peso da moralidade e o significado de se fazer o mal moralmente para alguém. A importância de se explicar a moralidade a partir das relações humanas, como faz o filósofo ao recorrer a exemplos de vida e da literatura, em detrimento da elaboração de fórmulas rígidas para o agir - à maneira daqueles de

SANTOS, Susie Kovalczyk dos. Raimond Gaita e a compreensão da moralidade a partir do reconhecimento da realidade do 
cujos padrões teóricos Gaita se afasta - é enfatizada por Pihlström, que escreve que

\begin{abstract}
[n]ão há ponto de vista externo a partir do qual poderíamos demonstrar que a moralidade é inescapável para nós. Podemos demonstrar isso apenas a partir do interior de nossa prática moral, ou do ponto de vista de estarmos engajados em [várias] práticas que crucialmente envolvem agência moral, e então não estaríamos fornecendo de modo algum uma 'demonstração', mas, em vez disso, uma reflexão acerca dos comprometimentos em funcionamento no tipo de vida moralmente preocupada [...]. (Pihlström, 2007, p. 108, tradução nossa).
\end{abstract}

O que Gaita entende por remorso não é simplesmente um sentimento ou uma atitude, mas um reconhecimento da realidade do outro, que esclarece através de uma analogia: quando se experimenta uma grande tristeza pela perda de alguém que se ama, a tristeza é um reconhecimento da realidade do outro através do choque de se ter perdido essa pessoa; o remorso, por sua vez, é o reconhecimento da realidade do outro através do choque de se ter cometido um erro considerável com relação a ela. No caso do assassinato, por exemplo, há "certo senso da individualidade da vítima que é interno à compreensão da assassina do significado moral do que ela fez, e isso é parte do que é estar ciente da realidade de outro ser humano" (GAITA, 2004, p. 52, tradução nossa). Além de ser uma forma de reconhecimento da realidade daquele com quem se errou, o remorso é o reconhecimento doloroso do significado da própria culpa, condição de quem comete algo moralmente errado, e que permanece com quem o sente - assombra-o.

Compreendendo o remorso como uma recordação do significado moral do que foi feito, não se pode explicar para alguém, escreve Gaita, o que é um problema moral desvinculado da inteligibilidade de um remorso genuíno. Assim, para esclarecer por que matar alguém é moralmente errado, recorre-se ao remorso que o assassino sente, ou que deveria sentir, diante da constatação do mal por ele provocado. Se alguém mata uma pessoa e diz que sabe o que fez, mas ainda assim não tem um remorso muito grande, em verdade, segundo o filósofo, essa pessoa não entende o que está dizendo, nem o que fez. Quanto aos casos patológicos em que um indivíduo não sente remorso ao realizar um mal para outrem, Gaita explica que a vida mental dessa pessoa carece da integridade interna necessária para responder às exigências da moralidade e que, no sentido relevante, ela não sabe o que faz. Um assassino que carece de sanidade mental, por exemplo, ainda que possa estar ciente da maneira como cometeu o assassinato e de que a vítima faleceu, não compreende de modo apropriado em que consiste tirar a vida de uma pessoa se estiver ausente a capacidade de sentir remorso, e, com ela, a capacidade dessa pessoa para entender o peso moral dos próprios atos.

$O$ entendimento moral requer daqueles que afirmam tê-lo que possam responder seriamente às demandas da moralidade, e esta não tem realidade para aqueles que não podem responder às suas exigências. A realidade do valor moral, de acordo com Gaita, é inseparável de sua realidade como um apelo em cada um: a moral convida a um engajamento, e a resposta séria a esse chamado consiste em reconhecer a realidade da moralidade.

SANTOS, Susie Kovalczyk dos. Raimond Gaita e a compreensão da moralidade a partir do reconhecimento da realidade do 


\section{A indissolubilidade do remorso genuíno}

Considere-se as seguintes situações em que, segundo Gaita, consegue-se minimizar os sofrimentos em geral. No entanto, o remorso genuíno, como será mostrado, não pode ter seu peso atenuado.

Primeiramente, Gaita escreve que é possível que se encontre uma espécie de consolo quando, diante de situações difíceis, se pensa ou fala em termos de comunidade humana e de companheirismo, o que exemplifica com o emprego do termo "nós" em expressões como "nós, mortais", "nós, que sofremos juntos" e "nós, desta nação". É o caso de povos cujas histórias são marcadas por alguma desgraça, e os indivíduos das comunidades que foram afetados por esses males encontram forças para reconstruir suas vidas em um senso de pertencimento a tal coletividade.

Em outros casos, o horror que se sente ao se observar o sofrimento de outra pessoa se dilui diante da constatação do sofrimento análogo de muitas outras. $O$ resultado, em tais situações, é que aquele que não protagoniza o sofrimento em questão, mas que o presencia ou observa, tem diminuído o senso da individualidade dos que sofrem. Ao pensar no sofrimento de um grande número de pessoas, não se costuma focar no sofrimento particular de cada uma das pessoas, mas no sofrimento do conjunto, o qual é despersonalizado. Eis o problema: desconsideradas as individualidades, desaparece também o peso do sofrimento dessas pessoas. Em geral, o relato de que há um número absurdo de pessoas morrendo em virtude da fome e de moléstias na África, por exemplo, comove menos que o relato acerca de uma criança específica que está padecendo dos mesmos males, no mesmo lugar.

Do ponto de vista de primeira pessoa, escapa-se mais dificilmente do sofrimento. É comum adquirir certa perspectiva ao se constatar que outros vivenciam certas situações difíceis análogas àquela pela qual se está passando, ou que os próprios erros e acertos são frequentemente ressignificados pelos sujeitos a partir da comparação com as capacidades verificadas naqueles que os cercam. Essa atenuação no modo como alguém se sentia inicialmente, uma espécie de consolo, se deve àquele senso, anteriormente apontado, de pertencimento a uma comunidade humana: muito daquilo que caracteriza uma pessoa enquanto tal são justamente suas limitações e capacidades, compartilhadas com grande parte da espécie humana. No entanto, quando se vivencia um sofrimento significativamente grande, dificilmente a dor de quem sofre será atenuada por esse senso de comunidade: muitos podem morrer e sofrer ao redor de uma pessoa; ainda assim, a constatação do sofrimento alheio não faz com que o próprio sofrimento se dilua em um senso indeterminado de sofrimento, embora possa oferecer algum consolo.

O remorso, em contraste, permanece com os sujeitos de uma forma radicalmente diferente dos demais sofrimentos. Segundo Gaita, quem sente remorso genuíno sempre rejeitará consolos baseados no reconhecimento da culpa alheia. Quando se reconhece a própria mortalidade e o quão frágil é a vida humana há uma espécie de consolo que não é encontrado quando alguém reconhece que fez algo errado, prejudicando outra pessoa, mesmo que essa pessoa que fez um mal e que está ciente disso saiba que outros também contribuíram para a realização do ato nocivo em questão, ou que ato análogo tenha sido praticado por pessoas consideradas muito virtuosas. Quando se está imerso em tristeza pela perda de alguém que se ama, é

SANTOS, Susie Kovalczyk dos. Raimond Gaita e a compreensão da moralidade a partir do reconhecimento da realidade do 
possível esperar que o tempo amenize tal sofrimento, mas é negado ao transcurso do tempo o poder de, por si só, curar o sofrimento do remorso que alguém carrega. A expiação do remorso requer, de acordo com Gaita, a contribuição de outros fatores, tais como o arrependimento, a compensação, o perdão e a punição.

Se, por outro lado, alguém que realizou algo, ou deixou de realizar, provocando um mal para outrem, é consolado pela ideia de que, quanto à situação, todos têm culpa, então essa pessoa não sente um remorso genuíno. Uma forma corrupta de remorso é descrita por Gaita na figura do ensimesmamento [selfabsorption], um tipo de egoísmo, que é a condição de alguém que está excessivamente preocupado consigo mesmo e com os próprios interesses, relegando tudo o mais. Tal noção é associada a um egocentrismo em que o sujeito que assim se encontra está tão imerso em si mesmo que o mundo simplesmente não importa, ou importa apenas na medida em que diz respeito a algum interesse seu. Uma pessoa pode estar nessa condição, como no exemplo dado por Gaita, quando absorta no medo da morte iminente, estando centrada em si a ponto de ignorar o mundo comum marcado pelo 'nós' do senso de pertencimento a uma comunidade humana. Nessa condição, afirma o autor, há um tipo de morte para o mundo.

Analogamente, no remorso também se morre para o mundo: aquele que sente remorso sofre com a constatação daquilo em que se tornou, descobrindo uma dimensão de si mesmo que não entra em comunhão consoladora com os outros. $O$ eu de quem sofre no remorso genuíno é radicalmente singular, não encontrando alívio em identificar que outros cometeram práticas semelhantes.

Alguns fenômenos morais, como virtudes e vícios, por exemplo, são estabelecidos mediante comparação: empiricamente se compreende os limites e as possibilidades humanas e, em função disso, delimitam-se os vícios e as virtudes, levando-se em conta o que é razoável esperar dos seres humanos. Gaita recorda que o teórico clássico da ética das virtudes, Aristóteles, falava em um limite para as acusações de covardia, tendo em conta que há sofrimentos que estão para além de qualquer capacidade humana de suportar. Se alguém julga com muita severidade as próprias falhas de caráter, afirma Gaita, pode-se chamar a atenção dessa pessoa para o fato de que é apenas humana e que, por isso, ela deve considerar suas falhas tendo em vista que outros se encontram em posição semelhante. Essa comparabilidade consoladora não se aplica, todavia, ao remorso: a constatação de que o que se fez de terrível foi também realizado por outra pessoa, ainda que por alguém considerado exemplar, não atenua a desolação do remorso.

\section{Remorso: o caso da holandesa}

No início do quarto capítulo de Good and Evil, intitulado Remorse and its lessons, Gaita traz o caso do relato fornecido por uma mulher holandesa para uma série de televisão chamada The World at War. Ao ser entrevistada, a holandesa contou que, durante a segunda guerra mundial, mandou embora três judeus que lhe pediram abrigo porque ela fazia parte de uma conspiração para matar Hitler e achava que, caso os abrigasse, poderia comprometer o plano em questão. Não passou muito tempo e eles foram mortos em um campo de concentração. Ela então disse que odiava Hitler por muitas coisas, mas principalmente por ele tê-la tornado uma

SANTOS, Susie Kovalczyk dos. Raimond Gaita e a compreensão da moralidade a partir do reconhecimento da realidade do 
assassina.

Esse é um dos exemplos que Gaita apresenta para ilustrar a importância do remorso para a moralidade. Diante desse caso, poder-se-ia argumentar que a holandesa fez o que considerou mais razoável face à situação por ela enfrentada, que a possibilidade de sua escolha resultar em prejuízo para aqueles que lhe pediram auxílio era um preço, ainda que considerável, a pagar pela oportunidade de cessar muito mais mortes com o assassinato do mentor do holocausto, que a mulher não foi diretamente responsável pela morte daquelas pessoas e que, por esses fatores, que a avaliação dela sobre si mesma foi demasiadamente rígida. Gaita, no entanto, considera razoável o juízo de si mesma feito pela holandesa, para o que ressalta dois aspectos.

O primeiro consiste em que, em um sentido, a holandesa não foi uma assassina: nenhuma corte a julgaria como assassina - ela sequer fez algo que pudesse conduzi-la à corte -, e ninguém, nem mesmo os familiares dos judeus que foram mortos, poderiam acusá-la seriamente de assassinato. Ainda assim, o segundo aspecto é o de que o juízo que a holandesa fez de si mesma revela a profundidade de sua escolha: aquelas pessoas precisavam de abrigo e ela recusou-se a abriga-los, o que resultou na morte deles, que poderia ter sido evitada se a escolha dela fosse diferente.

A partir disso, Gaita salienta uma fundamental distinção, a saber, que não é porque alguém não pode ser acusado de algo, no sentido que ninguém pode apontar que é culpado por certo ocorrido que resulta de ter realizado ou deixado de realizar uma escolha ou ação, que essa pessoa não é moralmente responsável pelo que fez, no sentido de que não deveria sentir remorso pelo erro cometido. A culpa tem várias conotações, assim como há vários tipos de atribuição de responsabilidade. Muitos dos problemas que Gaita afirma que várias teorias morais tradicionais possuem são por ele correlacionados a uma tendência dessas teorias para tratar culpabilidade e responsabilização moral como coisas muito próximas.

O autor reforça essa perspectiva por meio do exemplo de Édipo. O personagem da tragédia furou os próprios olhos ao descobrir que havia matado seu pai e se casado com sua mãe, o que indica um forte remorso. Do ponto de vista de um espectador, o mais sensato não é culpar Édipo pelo que fez sem ter a intenção, e sim sentir pena do fazedor do mal [evildoer] em que ele inadvertidamente se tornou. Nesse caso, sentir pena é a expressão de se atribuir responsabilidade moral a alguém. Gaita explica tal atribuição de responsabilidade em termos de situar aquele que fez um mal em uma resposta lúcida ao significado do que fez, o que não é o mesmo que acusá-lo ou que pensar que ele tem culpa com relação ao ocorrido.

Uma concepção de responsabilidade não precisa, portanto, estar atrelada a condições de culpabilidade. $O$ significado moral do que a pessoa faz está relacionado à resposta que fornece ao convite moral ao engajamento - o remorso. Retomando o exemplo, fornecido por Gaita, da holandesa: pode ser que se aponte que o que ela fez é relativamente insignificante, se colocado em perspectiva com os horrores do regime nazista, e que, por isso, a reação dela é inadequada - que ela tem razões mais fortes para odiar Hitler e que não é decente da parte dela atribuir tamanha importância ao próprio sentir-se culpada. Ainda que considere as execuções em massa ocorridas sob o regime nazista, a mudança de foco não resolve o problema: se ela realmente sente um remorso genuíno, o reconhecimento de que a sua recusa em abrigar essas pessoas

SANTOS, Susie Kovalczyk dos. Raimond Gaita e a compreensão da moralidade a partir do reconhecimento da realidade do 
resultou no assassinato delas é inconsolável. Deveria essa mulher odiar Hitler principalmente pelo assassinato de inúmeros seres humanos mediante seu comando, em vez de por "ter feito dela uma assassina"? Fosse o caso que seu remorso tivesse sido corrompido em uma forma de egoísmo, a resposta seria afirmativa. No entanto, a avaliação que fez de si mesma não deve ser interpretada como indicativo de que ela pouco se importava com o sofrimento alheio, mas como expressão do reconhecimento do significado do prejuízo causado àquelas pessoas.

\section{Comprometimento e reconhecimento}

Além do remorso, a concepção de Gaita leva outros sentimentos em consideração. A pena, por exemplo, é também expressão do reconhecimento de que se está diante de uma situação em que alguém fez um mal a outrem, contanto que seja sentida por um espectador. Isso porque a pena que o próprio sujeito que fez um mal pode sentir com relação a si mesmo consiste em autoindulgência, e a imersão em si mesmo o leva a desconsiderar, ou a deixar em segundo plano, o reconhecimento da realidade de quem ele prejudicou. De modo geral, Gaita defende que o compromisso moral assumido com os demais seres humanos exige o reconhecimento deles como possíveis alvos de remorso, bem como de amizade ou amor. Para que se compreenda de que maneira tais elementos são articulados pelo autor, convém resgatar alguns dos exemplos por ele fornecidos.

O primeiro exemplo é o caso de uma mulher que, tendo recentemente perdido seu filho, o qual caiu de um penhasco, afirmou, diante da cena de um documentário em que mães vietnamitas choravam por seus filhos, assassinados por bombardeios norte-americanos, que a situação dessas mães era diferente da sua, pois elas "simplesmente podem ter mais [filhos]" (GAITA, 2004, p. 332, tradução nossa).

O segundo exemplo é uma situação em que um então considerado protetor dos aborígenes, na Austrália dos anos 1930, James Isdell, coordenou um programa que consistia em retirar crianças mestiças do convívio de suas mães aborígenes e inseri-las em contextos em que provavelmente gerariam descendentes brancos de classe baixa. Questionado sobre como se sentia por arrancar as crianças de suas mães, Isdell não demonstrou qualquer arrependimento, afirmando que essas mulheres "logo se esqueceriam de sua prole" (GAITA, 2004, p. 333, tradução nossa).

O último exemplo não trata de um evento específico. Remete, antes, a um tipo de prática não tão estranha aos escravagistas, a saber, um senhor de escravos que estupra uma mulher escravizada e não considera que o mal que está fazendo se equipara ao mal que faria se estuprasse uma mulher branca, não escravizada.

O que há de comum aos três exemplos apresentados por Gaita, explica o autor, é a separação que aquela mulher, Isdell e o senhor de escravos fazem entre um "nós" e um "eles", em que todos que são compreendidos como "eles" não gozam do mesmo estatuto moral daqueles que integram o "nós". Os sujeitos dos três exemplos falham em reconhecer que essas pessoas que identificam como "eles" são insubstituíveis. Essa falha se insere em um contexto que, segundo ele, é comum ao desdém racista, em que parece aos sujeitos tais como os dos três exemplos que aqueles em relação aos quais se consideram diferentes, destacados, são vistos como se "nada [...] se desse profundamente com "eles" [as vítimas de suas discriminações];

SANTOS, Susie Kovalczyk dos. Raimond Gaita e a compreensão da moralidade a partir do reconhecimento da realidade do 
nem seus amores, nem suas tristezas, nem suas alegrias" (GAITA, 2004, p. 333, tradução nossa). Entretanto, os sujeitos dos exemplos não necessariamente falham em conceder que as vítimas de seu racismo preenchem os critérios filosoficamente requeridos para que alguém seja objeto de consideração moral. É mesmo provável que eles enxerguem essas pessoas como agentes racionais detentores de interesses, como vulneráveis e como mortais, o que leva Gaita a questionar o que falta a eles para que percebam o quão terrivelmente enganados estavam ao agir como descrito nos exemplos. A resposta, segundo o autor, consiste em que os três compreendem suas vítimas como não pertencentes ao mesmo espaço conceitual que eles julgam habitar.

\begin{abstract}
Apenas aqueles que reconhecemos como pertencentes ao mesmo domínio de significados que nós mesmos têm o poder de mostrar nossas vidas para nós, o poder de diretamente aprofundar, talvez por colocar em questão, nosso senso de quem e de que somos. Apenas a eles podemos genuinamente respeitar. (CORDNER, 2002, p. 159, tradução nossa).
\end{abstract}

Desse modo, ainda que as pessoas dos três exemplos admitam que suas vítimas possam sofrer, por exemplo, não é inteligível para aquelas que estas possam sofrer na mesma medida em que aquelas sofrem. Ver os outros como habitantes do mesmo espaço conceitual que nós, explica Gaita, é compreender cada uma dessas pessoas como o centro de uma consciência, é reconhecê-las como realidades independentes, capazes de nos exigir moralmente:

\begin{abstract}
Ver os outros como capazes de uma reflexiva, e mesmo mais intensa, responsividade individuadora para os fatos definidores da condição humana - nossa mortalidade, nossa sexualidade, nossa vulnerabilidade ao infortúnio - é vê-los como habitantes, junto a nós, do espaço do tipo de entendimento comum que frequentemente consideramos necessário se for para tratarmos os outros de maneira justa. É o tipo que temos em mente quando encorajamos nos outros e em nós mesmos um reconhecimento de nossa humanidade comum com todas as pessoas da Terra. Quando, como filósofos, discutimos a variedade de jeitos com que seres humanos vivem e valoram, frequentemente supomos que eles vivem e valoram no espaço daquele entendimento comum. (GAITA, 2004, p. 341, tradução nossa).
\end{abstract}

\title{
Considerações finais
}

Diante desse quadro, é possível questionar se para Gaita é preciso que se sinta remorso pela realização de um ato para que ele seja considerado moralmente errado. A resposta é negativa. $O$ crucial para que se decida pela reprovação de uma ação é que ela seja passível de remorso. Em outras palavras, a avaliação do valor moral de uma ação não depende de se quem a realizou sente remorso. Antes, deve-se perguntar se é concebível que alguém deva sentir remorso em circunstância desse tipo, caso tivesse realizado a ação. Se a resposta for positiva, então a ação é passível de reprovação. E qual a base para responder a tal pergunta? Um comum entendimento da moralidade. Seria ele inato? Segundo Gaita, não: essa compreensão pode ser ensinada. Ele inclusive menciona a afirmação aristotélica de que para que se julgue corretamente é necessário educar sentimento e caráter. Como pode ser feita essa

SANTOS, Susie Kovalczyk dos. Raimond Gaita e a compreensão da moralidade a partir do reconhecimento da realidade do 
educação não é objeto da presente exposição.

O distanciamento adotado por Gaita em relação às tradições morais modernas resulta em uma interessante posição para a explicação da moralidade. Afastando-se dos racionalistas, Gaita defende que escolhas, juízos e ações moralmente significativos não são pautados por um rígido senso de dever. Decisões morais não resultam, em última análise, de deliberações puramente racionais, culminando na adoção de vias de ação em função de uma formulação tal como a prescrita pelo imperativo categórico. Grande parcela dos seres humanos mentiria caso fosse necessário para salvar pessoas de serem torturadas, por exemplo, ao passo que a mentira é inaceitável no âmbito da teoria moral kantiana. É preciso cautela, no entanto, para evitar incorrer no erro apontado pela assim chamada Lei de Hume, segundo a qual não se pode derivar um deve de um é. Reitera-se, assim, o apoio à proposta de Gaita, esclarecendo que, além de não ser em função de deveres como os descobertos pelo imperativo categórico que decisões morais são tomadas, também não é desse modo que elas devem ser tomadas: situações diferentes demandam soluções diversas. Quanto ao caso da mentira: em geral, mentir é moralmente reprovável, mas há casos em que mentir pode ser a conduta mais adequada, como quando mentir resulta em salvar pessoas da tortura e não mentir implica em que elas serão torturadas.

Não se pretende, com isso, defender uma posição relativista. Como mencionado, Gaita defende que há uma espécie de pano de fundo segundo o qual se pode descobrir o que é fazer o bem ou o mal a alguém, que mesmo as diversas culturas que adotam padrões morais diferentes deveriam reconhecer. Gaita se afasta também do sentimentalismo moderno, do qual a filosofia moral humeana é um exemplo, a qual defende que a moralidade depende da capacidade de ser afetado pelo que os outros sentem, capacidade essa expressada através do princípio de simpatia. A proposta de Gaita representa um avanço com relação a essa concepção: o encontro genuinamente moral implica não que alguém aja em função de sentir o que o outro sente, o que poderia apontar para uma teoria de caráter egoísta. $O$ autor vai além ao defender que o encontro moral depende do reconhecimento sério do outro em sua individualidade. A pessoa que faz um mal para alguém, por exemplo, percebe a si mesma como alguém que fez o mal se reconhece sua vítima como objeto inteligível de remorso, e não por reverberar, nela mesma, o sofrimento da outra. $O$ sofrimento de quem faz o mal é o sofrimento perplexo diante da percepção da dimensão do sofrimento causado no outro. E se quem fez o mal não é atingido dessa maneira, ao menos deveria ser.

SANTOS, Susie Kovalczyk dos. Raimond Gaita e a compreensão da moralidade a partir do reconhecimento da realidade do 


\section{Referências bibliográficas}

BENTHAM, Jeremy. An Introduction to the Principles of Morals and Legislation. Edited by J. H. Burns, H. L. A. Hart. With a New Introduction by F. Rosen. Oxford: Clarendon Press, 1996.

CORDNER, Chistopher. Ethical Encounter: The Depth of Moral Meaning. Houndmills: Palgrave, 2002.

GAITA, Raimond. Good and Evil: An Absolute Conception. 2. ed. New York: Routledge, 2004.

KANT, Immanuel. Foundations of the Metaphysics of Morals. New York: BobbsMerrill, 1969.

MILL, John Stuart. Utilitarianism. Oxford: Oxford University Press, 1998.

PIHLSTRÖM, Sami. Transcendental guilt: On an Emotional Condition of Moral Experience. Journal of Religious Ethics, v. 35, n. 1, p. 87-111, mar., 2007.

Autor(a) para correspondência: Susie Kovalczyk dos Santos, Universidade Federal de Santa Maria, Departamento de Filosofia, Av. Romaima, 1000, CEP 97105-900 Bairro Camobi, Santa Maria, RS, Brasil.lczyk.susie@gmail.com 